Received: 29 May 2018

Accepted: 3 August 2018

Published online: 11 September 2018

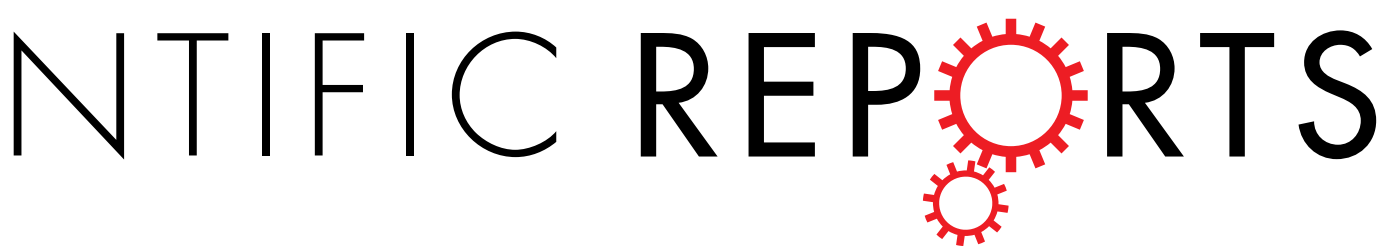

\title{
OPEN Transcriptomic analyses of cacao cell suspensions in light and dark provide target genes for controlled flavonoid production
}

Adriana M. Gallego ${ }^{1}$, Luisa F. Rojas $\mathbb{D}^{2}$, Oriana Parra ${ }^{1}$, Héctor A. Rodriguez ${ }^{3}$, Juan C. Mazo Rivas ${ }^{4}$, Aura Inés Urrea ${ }^{1}$, Lucía Atehortúa ${ }^{1}$, Andrew S. Fister $\mathbb{D}^{5}$, Mark J. Guiltinan ${ }^{5}$, Siela N. Maximova ${ }^{5}$ \& Natalia Pabón-Mora ${ }^{6}$

Catechins, including catechin (C) and epicatechin (E), are the main type of flavonoids in cacao seeds. They play important roles in plant defense and have been associated with human health benefits. Although flavonoid biosynthesis has been extensively studied using in vitro and in vivo models, the regulatory mechanisms controlling their accumulation under light/dark conditions remain poorly understood. To identify differences in flavonoid biosynthesis (particularly catechins) under different light treatments, we used cacao cell suspensions exposed to white-blue light and darkness during 14 days. RNA-Seq was applied to evaluate differential gene expression. Our results indicate that light can effectively regulate flavonoid profiles, inducing a faster accumulation of phenolic compounds and shifting $\mathrm{E} / \mathrm{C}$ ratios, in particular as a response to switching from white to blue light. The results demonstrated that $H Y 5, M Y B 12, A N R$ and $L A R$ were differentially regulated under light/dark conditions and could be targeted by overexpression aiming to improve catechin synthesis in cell cultures. In conclusion, our RNA-Seq analysis of cacao cells cultured under different light conditions provides a platform to dissect key aspects into the genetic regulatory network of flavonoids. These lightresponsive candidate genes can be used further to modulate the flavonoid production in in vitro systems with value-added characteristics.

Cacao seeds are a rich source of polyphenols, particularly flavonoids ${ }^{1}$. Flavonoids play important roles in plant defenses against herbivory ${ }^{2}$, pathogens ${ }^{3,4}$, cold $^{5}$, drought ${ }^{6}$, high light intensity ${ }^{7}$ and UV radiation ${ }^{8}$. These compounds are often produced in response to different stressors ${ }^{9,10}$. The main groups of flavonoids in cacao include catechins (flavan-3-ols) (37\%), proanthocyanidins (PAs) $(58 \%)$ and anthocyanins $(4 \%)^{11}$. Among the catechins, $(-)$ - epicatechin is more abundant than $(+)$ - catechin, representing $35 \%$ of the polyphenol content in unfermented cacao beans ${ }^{12}$. Catechins serve also as monomeric units for the construction of proanthocyanidin oligomers and share the same substrate for the production of anthocyanins ${ }^{9}$. Cacao flavonoids, specifically catechins and their oligomers contribute to the chocolate quality, as they are responsible for the astringency ${ }^{13}$. Additionally, they have been associated with potential benefits for human health ${ }^{14}$, particularly in reducing cardiovascular disease ${ }^{15}$.

Flavonoid production is regulated at the transcriptional level by different families of transcription factors, in particular the multimeric unit formed by members of the R2R3-MYBs, bHLHs and WD40s, called MBW complexes $^{16,17}$. The early biosynthetic steps are transcriptionally regulated by MYB11, MYB12, and MYB111, three closely related R2R3-MYB proteins. Specific combinations of MBW complexes like the MYB protein

${ }^{1}$ Universidad de Antioquia, Grupo de Biotecnología, Medellín, Colombia. ${ }^{2}$ Universidad de Antioquia, Grupo de Biotecnología-Escuela de Microbiología, Medellín, Colombia. ${ }^{3}$ Corporación para Investigaciones Biológicas and Departamento de Ciencias Agronómicas, Facultad de Ciencias Agrarias, Universidad Nacional de Colombia, UNALMED-CIB, Medellín, Colombia. ${ }^{4}$ Compañía Nacional de Chocolates, Medellín, Colombia. ${ }^{5}$ Department of Plant Science and Huck Institutes of Life Sciences, The Pennsylvania State University, University Park, PA, United States. ${ }^{6}$ Universidad de Antioquia, Instituto de Biología, Grupo Evo-Devo en Plantas, Medellín, Colombia. Correspondence and requests for materials should be addressed to S.N.M. (email: snm104@psu.edu) or N.P.-M. (email: lucia.pabon@ udea.edu.co) 
TRANSPARENT TESTA 2 (TT2), the bHLH protein TT8 (TRANSPARENT TESTA 8) and the WD40 protein TRANSPARENT TESTA GLABROUS1 (TTG1) control the late reactions of the pathway ${ }^{18,19}$. Functional studies of MBW complexes have been done extensively in maize (Zea mays), petunia (Petunia hybrida), snapdragon (Antirrhinum majus), and Arabidopsis (Arabidopsis thaliana) ${ }^{20-24}$. In cacao, functional characterization of the putative MYB TT2-like has been done by functional complementation of Arabidopsis mutants ${ }^{25,26}$.

MBW complexes can directly activate downstream structural genes to turn on flavonoid biosynthe$\operatorname{sis}^{27-29}$. Thus, chalcone synthase $(\mathrm{CHS})$, chalcone isomerase $(\mathrm{CHI})$, flavanone 3 hydroxylase $(\mathrm{F} 3 \mathrm{H})$, flavonoid $3^{\prime}$-hydroxylase $\left(F 3^{\prime} H\right)$, flavonoid $3^{\prime} 5^{\prime}$-hydroxylase, and flavanol synthase (FLS) are early genes in the pathway. Downstream, another set of genes including dihydroflavonol 4-reductase (DFR), UDP-glucose flavonol 3-O glucosyl transferase (UFGT), anthocyanidin synthase $(A N S)$, anthocyanidin reductase (ANR), and leucoanthocyanidin reductase $(L A R)$ participate as late genes in the pathway ${ }^{30}$. The activation of $A N S$, ANR, and LAR control the production of catechins $\left((+)\right.$ - catechin and (-)- epicatechin) in cacao $^{25}$. In addition, transport genes such as Multidrug and Toxic Compound Extrusion (MATE) as well as ABC transporters and the glutathione S-transferase (GST) factors have been linked to flavonoid transport and accumulation ${ }^{31}$.

The accumulation of flavonoids in vivo can be regulated by environmental conditions, including light ${ }^{32-34}$. Light is perceived by plant photoreceptors, which are localized in the cytoplasm and respond to light stimuli by initiating a cascade of effectors, such as GTP binding proteins (G-proteins) and protein kinases ${ }^{35}$. The rapid induction of flavonoid biosynthesis generally observed under high light intensity demonstrates the key role of flavonoids in photoprotection ${ }^{36}$. Whereas in most plants flavonoid biosynthesis is affected by light ${ }^{33}$, there are some examples of flavonoid accumulation in a light independent manner, as is the case of anthocyanin accumulation during ripening of mangosteen (Garcinia mangostana) ${ }^{37}$ and the induction of differential flavonoid profiles in panicles of red rice in the $\mathrm{dark}^{38}$.

Understanding how light regulates flavonoid biosynthesis in planta can be challenging given the lack of full control over environmental variables, the divergent responses of flavonoid accumulation among plant organs, as well as species and even cultivar- specific responses to light ${ }^{39-41}$. Instead, cell cultures provide a powerful platform for assessing genetic changes associated with the production and accumulation of secondary metabolites such as flavonoids under light treatments thanks to characteristics like its uniformity, homogeneity, repeatability, the absence of developmental processes, and slow systemic effects between cells ${ }^{42}$. Cell cultures override most limitations of studying flavonoid accumulation in planta and allow to directly test the influence of light in flavonoid production. In vitro and in vivo, flavonoids are known to be induced and accumulated by light stress using LED lights in distinct plant species, particularly blue LED light ${ }^{43-45}$. Flavonoids are also known to be produced in the dark, linked to the induction of cell death and the activity of oxidative enzymes ${ }^{46-49}$. Yet, the influence of light on flavonoid accumulation in in vitro systems is still poorly understood, even though catechin production is feasible in cacao cell suspensions and provides a harvesting material for flavonoids ${ }^{47}$.

To better assess the expression changes of genes involved in flavonoid synthesis under light and dark treatments in vitro, we sequenced and analyzed 36 transcriptomic profiles of cacao cell suspensions cultured under 9 light and dark treatments. Specifically, cell cultures were subjected to two treatments: (1) white LED light followed by blue LED light (hereafter referred to as W-B) and (2) darkness (hereafter referred to as D) along a time course of 14 days (Fig. 1). Our analysis demonstrated that genes associated with light signaling, transcription factors and structural genes of the flavonoid pathway were differentially expressed in both treatments. Additionally, co-expression networks were built to identify genes associated with the late structural genes in the flavonoid pathway. These results provide additional information in the flavonoid genetic network and suggest candidate genes that serve as targets for metabolic engineering in the production of flavonoids in light/dark conditions.

\section{Results}

Effect of light treatments on accumulation of total flavonoids in in vitro cacao cultures. The accumulation of flavonoids was evaluated in cacao cell suspensions in vitro under the two conditions white-blue LED lights (W-B) and dark (D) (Fig. 1a). Considering that flavonoid biosynthesis occurs slowly and dramatic shifts have not been observed after one day ${ }^{27}$, we sampled at three time points corresponding to $0,7,8$ and 14 days after culture initiation. Compared to day $0(3.187 \mathrm{mg} / \mathrm{g})$, both W-B and D treatments significantly increased total polyphenol accumulation to $16.39 \mathrm{mg} / \mathrm{g}$ and $19.19 \mathrm{mg} / \mathrm{g}$ respectively $(\mathrm{p}<0.0001)$ (Fig. 1b). Similarly, total proanthocyanidins (PAs) content showed significant changes from day 0 to day 14 . Interestingly, we observed a trend in increasing accumulation of PAs resulting from both light and dark treatments, being higher for light than dark (Supplementary Fig. S1). Epicatechin significantly increased along the time course for both treatments. Catechin content was significantly higher ( $\mathrm{t}$-test $\mathrm{p}<0.05)$ in $\mathrm{W}$-B compared to D condition at day 14 (Fig. 1c).

RNA-Seq analysis and functional annotation. High-throughput sequencing of transcripts from the cell suspensions samples generated 16.91-26.61 million 100-bp single-end reads from each library. After the quality filtering process, $98.90 \%$ of the reads remained, with a Q38 percentage $\geq 80 \%$. The counts of clean reads per library ranged from 16.57 to $26.34 \mathrm{M}$. The percentages of mapped reads were $43.72-88.49 \%$ (Supplementary Table S1). Reads mapped to approximately 17,500 gene models in each library, about $73.93 \%$ of the 23,670 genes present in V2 Criollo cacao genome database (http://cocoa-genome-hub.southgreen.fr/). In total, 17,871 known genes were identified, corresponding to $75.50 \%$ of cacao genes. GO terms showed that most genes were grouped in cell part (86\%) and cell (86\%) for the cellular component, cellular process (59\%) and metabolic process (51\%) for biological process component, and binding (50\%) for molecular function (Supplementary Fig. S2). COG analyses identified 3033 genes in general function prediction (R), 1429 in transcription (K) and 347 genes in secondary metabolites biosynthesis, transport and catabolism (Q) (Supplementary Fig. S3). 


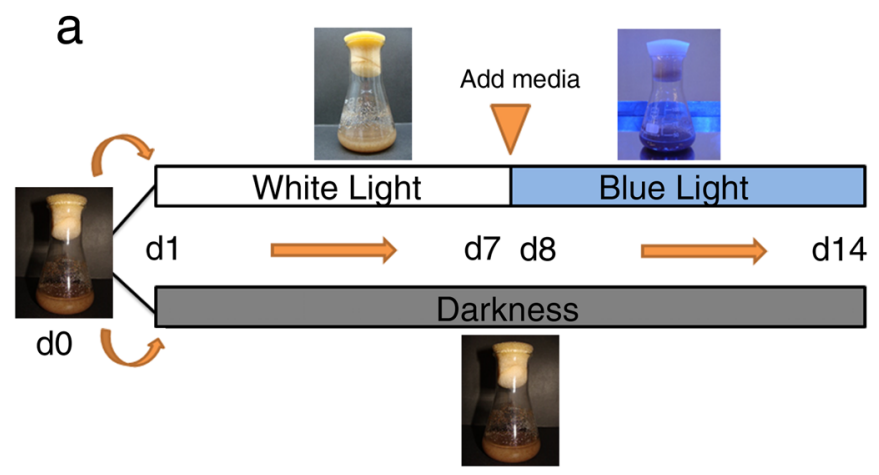

b

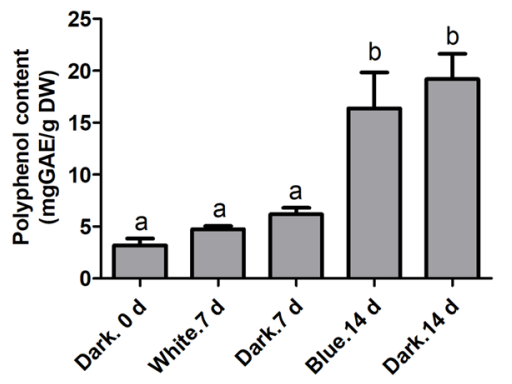

C

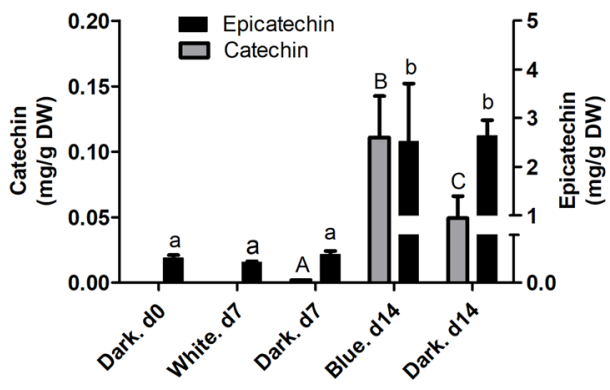

Figure 1. Experimental setup and chemical quantifications for cacao cell suspensions under light treatments and polyphenol content. (a) Diagram showing treatments with white - blue LED lights (top) versus dark (bottom) along the 14-day time course. (b) Measurements of total polyphenol content. (c) Measurements of catechin and epicatechin contents during the time course experiment. d: day. The graph shows the average values from three independently sampled cell suspensions. Error bars indicate the standard deviation. Different letters between each treatment indicate $\mathrm{p}<0.05$.

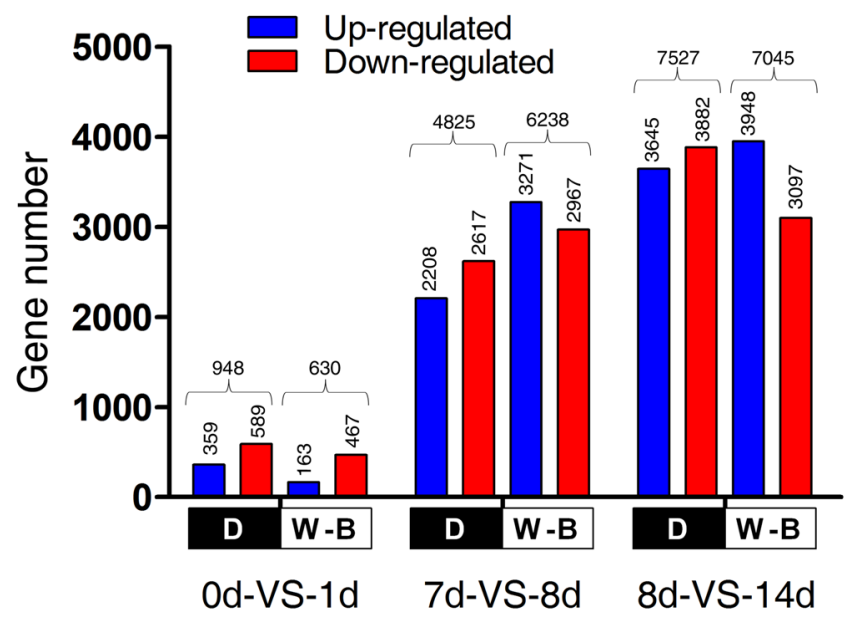

Figure 2. Total number of DEGs in pairwise comparisons over the time course for all cell cultures sequenced under both W-B and D conditions. Values above columns represent total DEGs, up and down regulated genes. d: day.

Differential gene expression in light versus dark over time. A total of 10,446 non-redundant differentially expressed genes (DEGs) were identified between W-B and D conditions during the entire time course of the experiment. From these, 6,640 DEGs were found in both treatments, whereas 1,816 DEGs were exclusively expressed in W-B and 1,989 were expressed only in D. In the three pairwise comparisons (by days) we identified 948 (d0-VS-d1), 4,825 (d7-VS-d8) and 7,527 (d8-VS-d14) in D and 630, 6,238 and 7,045 respectively in W-B. We found two opposite trends in gene expression for both treatments. More genes were down-regulated for $\mathrm{D}(7,088$ DEGS) along the progression of the time course compared to $\mathrm{W}$ - $\mathrm{B}$ where more up-regulated genes (7,382 DEGs), except for the first comparison of day 0 to day 1 (Fig. 2). 
a

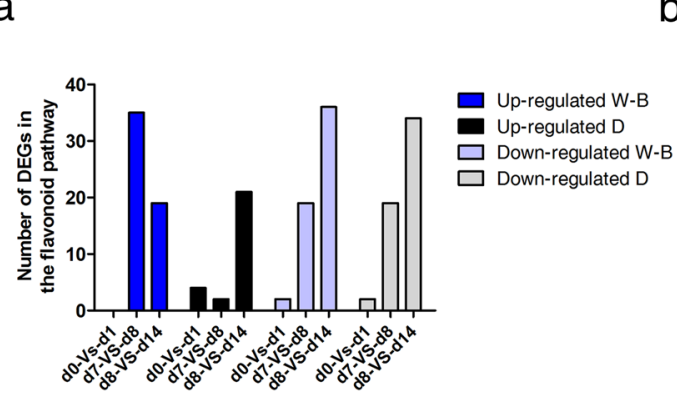

C

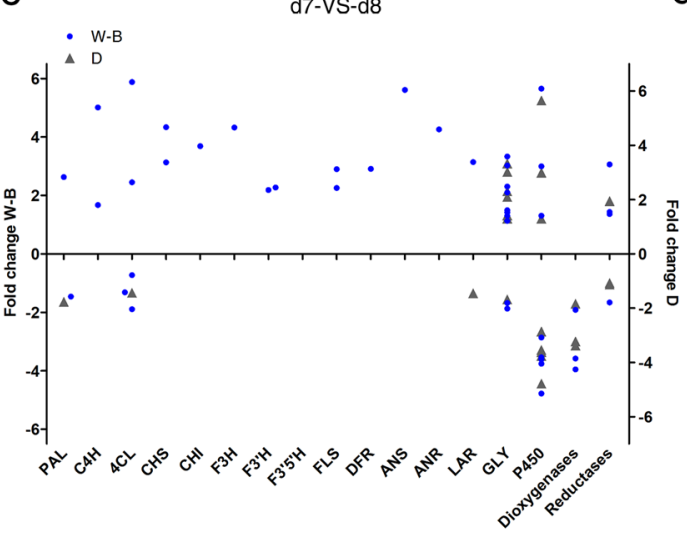

b

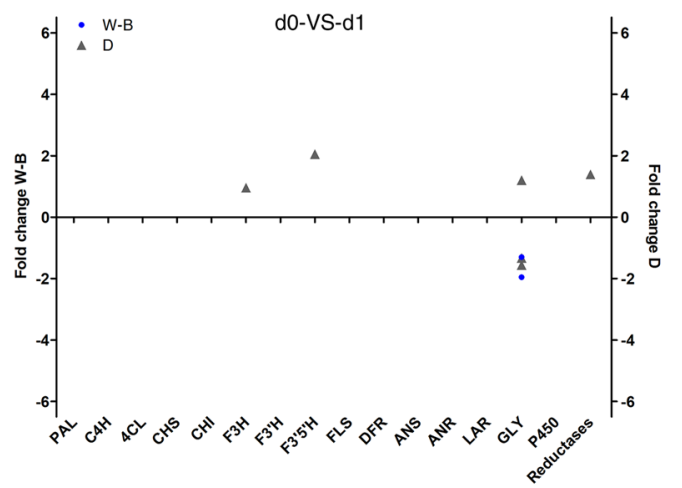

d

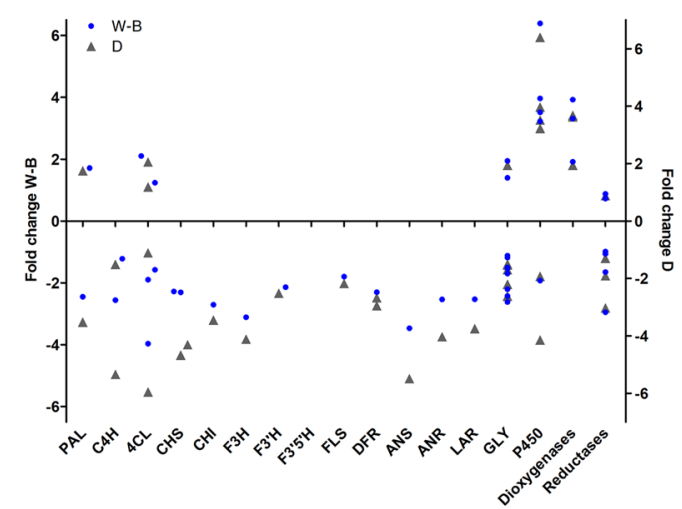

Figure 3. Diagrams of changes in expression levels of differentially expressed flavonoid genes. (a) Number of up and down regulated structural genes in the flavonoid pathway. (b-d) Fold changes for flavonoid genes at d0VS-d1, d7-VS-d8 and d8-VS-d14. Blue dots for treatment W-B. Gray triangles for treatment D. Abbreviations: day (d), phenylalanine ammonia lyase $(\mathrm{PAL})$; cinnamate 4-hydroxylase $(\mathrm{C} 4 \mathrm{H})$; 4-coumarate coenzyme A ligase (4CL); chalcone synthase (CHS); chalcone isomerase (CHI); flavanone 3-hydroxylase (F3H); flavanone $3^{\prime}$-hydroxylase $\left(\mathrm{F}^{\prime} \mathrm{H}\right)$; Flavonoid-3', $5^{\prime}$-hydroxylase $\left(\mathrm{F}^{\prime} 5^{\prime} \mathrm{H}\right)$; Flavonol synthase (FLS); dihydroflavonol4-reductase (DFR); anthocyanidin synthase (ANS); anthocyanidin reductase (ANR); leucoanthocyanidin reductase (LAR); Glycosiltransferases (GLY); Cytochrome P450 enzymes (P450).

Gene ontology analysis for DEGs showed that for the W-B treatment, cellular process, metabolic process, cell part, and cell, constituted the most abundant categories in all the three pairwise comparisons (Supplementary Fig. S4). By contrast, the same analysis in samples subjected to D treatment showed that the gene categories that are more represented include immune system process, growth, cell part and cell (Supplementary Fig. S5).

Pathway analysis. To determine the effect of W-B and D treatments on gene expression associated to flavonoid production and accumulation in cell cultures, we performed a KEGG enrichment for DEGs in the three pairwise comparisons. KEGG analysis resulted in 66 and 63 pathways for W-B and D, respectively (Supplementary Table S2). For W-B, the most abundant sequences were found in protein processing (38 DEGs, $19.7 \%)$ in d0-VS-d1, and metabolic pathways (673, 36.14\% and 734 DEGs, 39.41\%) for d7-VS-d8 and d8-VS-d14 respectively. In contrast, for the $\mathrm{D}$ condition, plant-pathogen interaction (14 DEGs, 11.2\%) was enriched at d0-VS-d1 and metabolic pathways (506 DEGs, 27.17\% and 706, 37.91\%) were enriched for d7-VS-d8 and d8-VS-d14 respectively. Flavonoid biosynthesis was only enriched in the W-B treatment in d7-VS-d8, coinciding with the change from white to blue light.

We further analyzed the DEGs using MapMan to classify individual gene responses in secondary metabolism and the flavonoid pathways. Interestingly, a higher variation in the number of genes of the flavonoid pathway were found for up regulated genes between the pairwise comparisons for both W-B and D compared with down-regulated genes (Fig. 3a). For W-B in the change from dark to white light at d0-VS-d1, two UDP-glucosyltransferases genes were down-regulated (Fig. 3b). Interestingly, after the change from white to blue light in $\mathrm{d} 7$-VS-d8 comparison, most of the flavonoid synthesis structural genes were up-regulated. In particular, late genes $A N R$ and $A N S$ had $\log _{2}$ fold changes (LFC) of 4.2 and 5.6, respectively (Fig. 3c). During blue light treatment, comparison $\mathrm{d} 8$-VS-d14, the opposite pattern was found, with most of the structural genes reported as down-regulated, including the late genes ANS, ANR and LAR (LFC $-3.4,-2.5$ and -2.5 respectively) (Fig. 3d, Supplementary Table S3).

In the D condition at d0-VS-d1, the genes $F 3 H, F 3^{\prime} H, F L S$ and $D F R$ were up-regulated especially $F 3^{\prime} H$ with 2.05 LFC (Fig. 3a,b). At d7-VS-d8, these same genes were down-regulated including an active copy of the LAR 

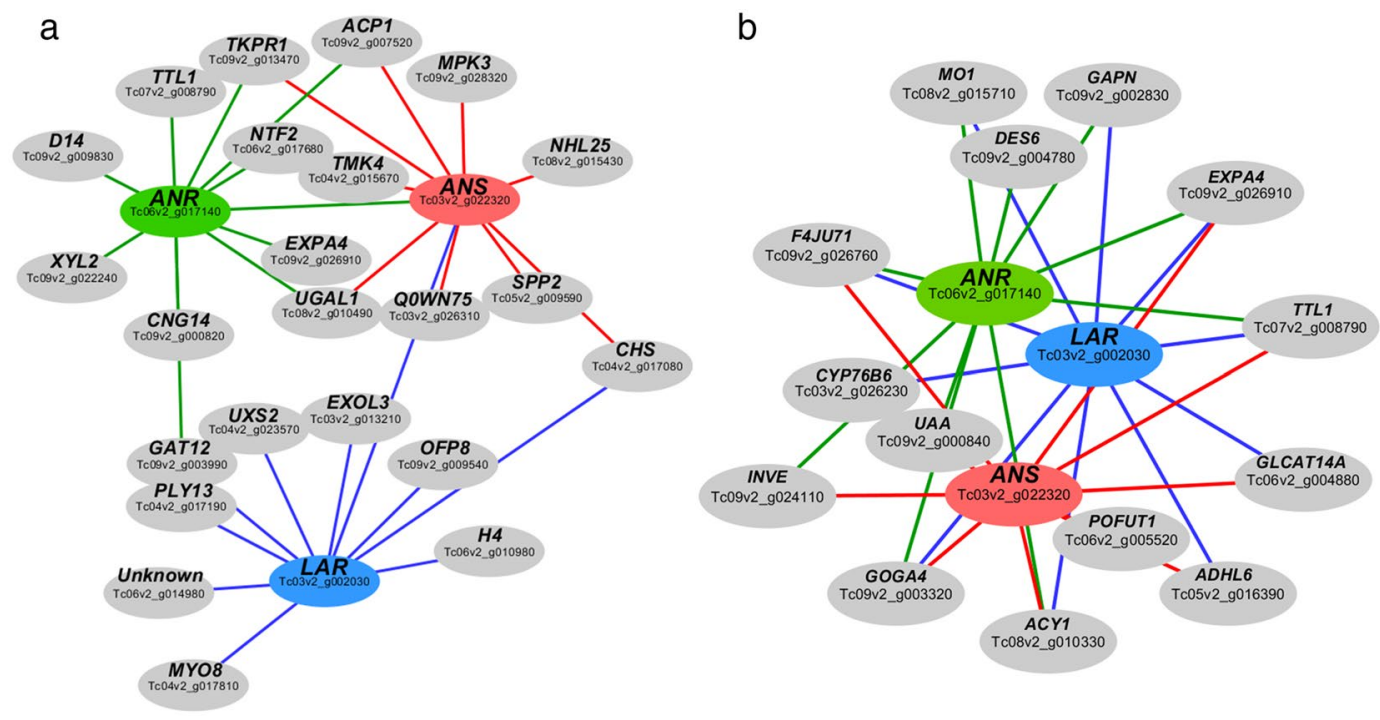

Figure 4. Co-expression network using late genes of flavonoid pathway $A N S, A N R$ and $L A R$ as seed nodes. (a) Subnetwork for W-B in the "Indianred4" module. (b) Subnetwork for D in the "Darkgreen" module. In both cases using top 30 of genes co-expressing with late biosynthetic genes.

gene (LFC -1.4) (Fig. 3c). At the d8-VS-d14 most of the structural genes were down-regulated particularly late genes like ANS, ANR and LAR with LFC $-5.48,-4.0,-3.7$ respectively (Fig. 3d, Supplementary Table S3). Our results indicate that shift from white to blue light affected gene expression faster than permanent growth in the dark. The opposite trend in gene expression was observed when we compared $\mathrm{d} 8$ to $\mathrm{d} 14$ time points that could be resulting from negative feedback following long-term exposure to light. We further analyzed the top 30 up- and down- regulated DEGs at d8-VS-d14 for both treatments, searching putative genes linked to changes in the catechin profile. As a result, $\mathrm{ANS}$ and $\mathrm{CH} 4$ were found strongly downregulated in the D treatment (Supplementary Table S4)

Analysis of late genes of flavonoid biosynthesis using Co-expression networks. To identify genes co-regulated with flavonoid late genes directly producing catechins (flavan-3 ols), we performed co-expression network analysis using $\mathrm{WGCNA}^{48}$. A total of 16,634 and 16,526 genes for W-B and D respectively were used to perform the co-expression network. We generated 17 (W-B) and 19 (D) modules after creating the adjacency matrix (Supplementary Figs S6 and S7).

For both treatments W-B and D, we selected the top 10 genes (i.e. those with the stronger pairwise correlations) co-expressing with each one of the late genes in flavonoid biosynthesis to be visualized with Cytoscape (Fig. 4). For the W-B network, late genes co-expressing with genes associated to different biological processes are detailed in Supplementary Table S5. Interestingly, LAR and ANR co-expressed with GAT12, a light responsive and ANS co-expressed with flavonoid pathway genes like CHS and ANR. Additionally, ANS co-expressed with both $L A R$ and $A N R$, while no co-expression between $A N R$ and $L A R$ was detected (Fig. 4a). For D, the co-expression network is detailed in Supplementary Table S6. Interestingly, genes like CYP76B6 (secondary metabolism), INVE (sucrose metabolism) and DES6 (fatty acid metabolism) co-expressed with LAR, ANS and ANR respectively. In D network, more genes co-expressed simultaneously with all late genes indicating a common and shared processes in the dark, opposite to the light network, where late genes had more specialized partners (Fig. 4b).

Analysis of differential expression of transcription factor genes. We next analyzed differential expression of genes encoding for transcription factors (TFs) involved in control of light induced responses as well as the onset of metabolism under stress. By using Plant Transcription Factor Database with our DEGs, we identified 578 non- redundant transcription factors (TFs) in our total set of DEGs for W-B and D conditions. For W-B, 83 TFs were common for d0-VS-d1, d7-VS-d8, and 264 overlapped for d7-VS-d8 and d8-VS-d14 timepoints where blue light responsive transcription factors are likely to be found. For D, 48 TFs were shared between d0-VS-d1 and d7-VS-d8, and 182 overlapped between d7-VS-d8 and d8-VS-d14. Interestingly, more transcription factors were expressed under W-B (532) than D (390) suggesting higher downstream activation under light treatments. Several families of TFs including MYB, bHLH, ERF, WRKY, and NAC were found overrepresented in the DEGs based on the normalized counts (Table 1, Supplementary Table S7).

To better assess which TFs could directly or indirectly regulate flavonoid accumulation, we focused in members of the MBW (MYB/bHLH/WD40) complex in all time points. In particular, our analyses targeted MYB genes because they have been linked to flavonoid biosynthesis in functional analyses in other plant species. To assess homology for the DEG MYB genes, we included all 53 differentially expressed MYB cacao genes in a phylogenetic analysis with all the MYBs reported for Arabidopsis (Supplementary Fig. S8). Then, we performed a heatmap and a second phylogenetic tree using 12 selected cacao MYB genes specifically involved in flavonoid biosynthesis (Fig. 5a). We classified them into 4 types following previous classifications ${ }^{49}$. Our results rescued 


\begin{tabular}{|l|l|}
\hline Transcription factor family & Number of members \\
\hline AGAMOUS-like & 8 \\
\hline Auxin response factor & 10 \\
\hline B3 family protein & 10 \\
\hline bHLH family protein & 45 \\
\hline C2H2 family protein & 17 \\
\hline C3H family protein & 14 \\
\hline ERF family protein & 36 \\
\hline FAR1-related sequence & 14 \\
\hline G2-like family protein & 18 \\
\hline GATA transcription factor & 8 \\
\hline LOB domain-containing protein & 10 \\
\hline MYB family protein & 53 \\
\hline NAC family protein & 32 \\
\hline Nuclear factor Y & 12 \\
\hline SCARECROW-like & 9 \\
\hline Trihelix family protein & 9 \\
\hline WRKY DNA-binding protein & 34 \\
\hline Zinc Finger family (ZnF) & 8 \\
\hline
\end{tabular}

Table 1. Overrepresented transcription factor families in $\mathrm{W}-\mathrm{B}$ and $\mathrm{D}$ conditions.

those related with the subgroup 7 (S7; Flavonol biosynthesis), S5 (Proanthocyanidins biosynthesis) and S4 (Transcriptional repressors of phenylpropanoid biosynthesis). The group with most DEGs was S5, with six cacao genes up-regulated early in the W-B and D treatments at d0 and d1. One gene of the S7 group (Tc01v2_t025900, $M Y B 12$ ) was up-regulated at $\mathrm{d} 1$ and $\mathrm{d} 7$ only in W-B and six genes of the S4 group were up-regulated at day 7 and day 14 in both treatments. Finally, genes associated with MYB5 were not found (Fig. 5b).

In order to assess homology for the copies in cacao, we performed a phylogenetic analysis using all the bHLH genes reported for Arabidopsis and the 45 bHLH differentially expressed for cacao (Supplementary Fig. S9). Among the bHLH genes involved in flavonoid biosynthesis TT8, GL3 (Glabra3), and EGL3 (Enhancer of Glabra3) have been well characterized in Arabidopsis. We searched for their homologs in our transcriptomes, and we found that AtGL3 and AtEGL3 blasted to Tc03v2_t023390 in cacao. We found that this gene is expressed in all time points in both W-B and D, but did not show differential expression. Similarly, the homolog of TT8, Tc01v2 t023340, was not differentially expressed in our transcriptomes. Interestingly, in our phylogeny of bHLHs, two genes including the transcription factor MYC2 (Tc03v2_t018930) and bHLH3 (Tc01v2_t021940) were nested with $A t G L 3$ and AtEGL3 and AtTT8 and both genes were upregulated at day 7 and day 14 for W-B and D, respectively. Finally, as for the WD40 homologs of the MBW complexes, we searched the homolog of Arabidopsis of TRANSPARENT TESTA GLABRA 1, TTG1 in cacao (Tc03v2_t017390). This gene showed one peak of upregulation early for both treatments at day 1 .

Analysis of gene expression of light signal perception and signaling genes. Because light perception has been linked to flavonoid accumulation in plants $\mathrm{s}^{33,50}$, we next explored regulation of light responsive genes in each time point using heat maps. From all DEGs we selected genes encoding for photoreceptors (i.e. phytochromes - PHYs, cryptochromes - CRYs, and Uv-B Resistance 8 - UVR8) and downstream light signaling genes such as Constitutive Photomorphogenesis 1 and 10 (COP1, COP10), Suppressor Of PHYA (SPA1), Phytochrome Kinase Substrate 1 (PKS1) and Long Hypocotyl 5 (HY5) (Fig. 6). In general, most of photoreceptors showed two peaks of upregulation, at $\mathrm{d} 7$ and $\mathrm{d} 14$, in W-B when compared to D. CRY3 showed a strong up-regulation at $\mathrm{d} 1$ and $\mathrm{d} 7$ only in W-B. In D, PHYB, PHYE and COP10 showed one peak up-regulation, particularly PHYE. Genes CRY2, UVR8 and PKS1 showed two peaks at d7 and d14. One of the copies of COP1, Tc01v2_t015370 was upregulated in both W-B and D at d0 and d1, instead the other copy, Tc01v2_t015410 was upregulated only in light at d7. Interestingly, CRY1, COP1, SPA1 and HY5 were upregulated only in $\mathrm{W}-\mathrm{B}$, in a manner opposite to PKS1 been upregulated exclusively in D.

qRT-PCR Validation of Differentially Expressed Genes. To validate further the RNA-seq results, we randomly selected 8 DEGs: CHS, CHI, DFR, ANS, ANR, LAR, NAC and TT2-like for qRT-PCR analysis 0, 1, 7, 8 and 14 days after treatment (Supplementary Table S8). The qRT-PCR showed the same patterns as the transcript abundance as determined by RNA-seq (Supplementary Fig. S10).

\section{Discussion}

The proposed model for light-induced flavonoid biosynthesis includes a multi-level regulation by photoreceptors, negative regulators (i.e. COP1), light-response effectors (i.e. HY5), transcription factor complexes (MYB-bHLH-WD40, MBW), and structural genes directly promoting flavonoid biosynthesis (incl. ANR, ANS, $L A R)^{50}$. The discussion will follow this direction in order to explain the progressive genetic bases resulting in an increased content of phenolic compounds in cacao cell suspensions in both W-B and D treatments along the time 


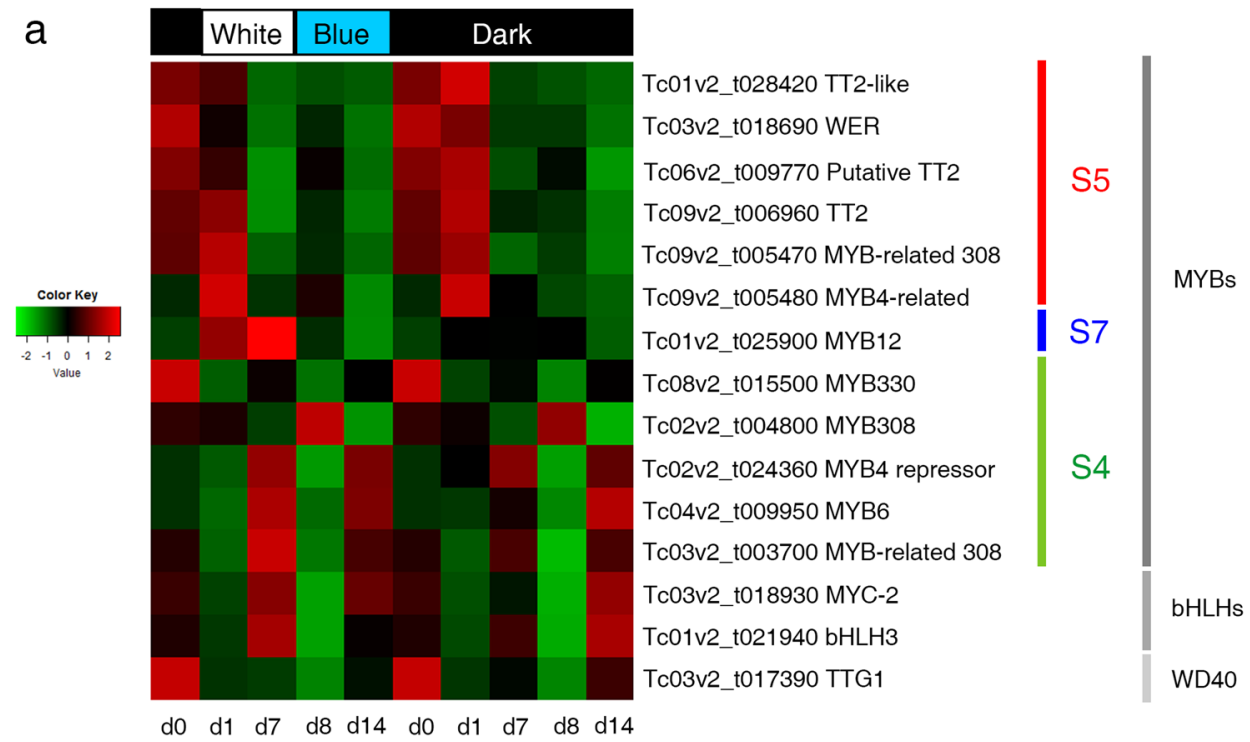

b

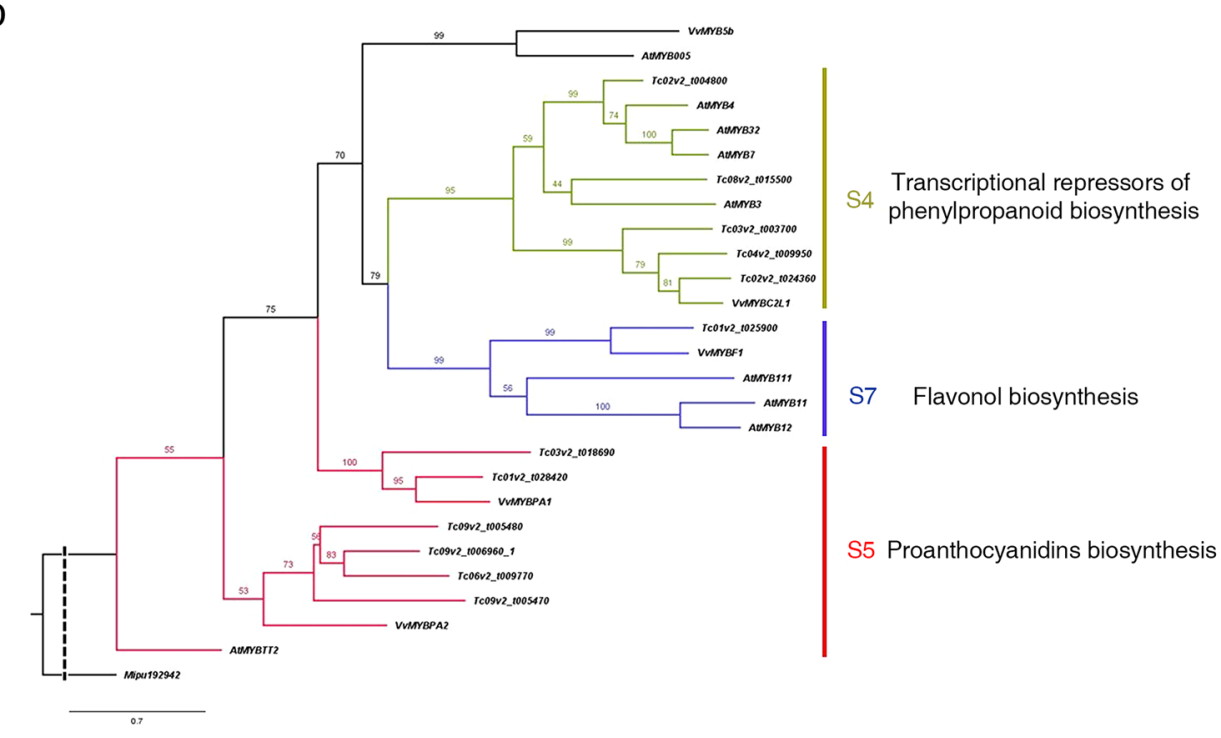

Figure 5. Expression patterns of MYB, bHLH and WD40 transcription factors and phylogeny of selected MYBs in cacao. (a) Heat map illustrating expression patterns of selected transcription factors of MBW complex at W-B and D treatment. (b) Phylogenetic analysis of selected MYBs genes associated with flavonoid pathway for cacao, Arabidopsis and grape. Abbreviations: day (d). Dotted line: shortened evolutionary distance.

course of 14 days. To identify the genetic underpinnings of accumulation of (+)-catechin in W-B treatment we will also discuss co-expression networks constructed for major key structural late genes like ANR, ANS and LAR.

Our study demonstrated that $C R Y 1, C O P 1, S P A 1$ and $H Y 5$ were strongly up-regulated only in W-B, in particular under white light at day 7 . This is consistent with the known model for light perception and signaling, where the COP1/SPA complex interacts with photoreceptors like $C R Y 1^{51}$ leading to a self-regulatory feedback loop by dissociation of COP ${ }^{33,52}$. Low abundance of COP1 in the nucleus allows $H Y 5$, the master positive regulator of light signaling, to accumulate and directly activate the flavonoid pathway, by binding to the promoter of $C H S^{33,53-}$ 55. Our data suggested that the light signaling pathway that controls flavonoid biosynthesis is maintained in the cell cultures, as it occurs in plants ${ }^{33}$. In contrast, fewer genes, including PHYE, COP10 and PKS1, were strongly up-regulated in D with PKS1 overexpressed exclusively under this condition. The up-regulation of PHYE has also been detected under low fluence responses in promoting germination in Arabidopsis ${ }^{56}$. PKS1 has been related to signal transduction of PHYA and PHYB in Arabidopsis ${ }^{57}$, however in cacao cell suspensions is only active in the dark, whereas in Arabidopsis has been shown to occur both in light and in dark and there are no additional reports on dark stimulated transcription for $P K S 1$, which would point to a light independent role of $P K S 1$, likely unlinked to $P H Y$ activation in cacao cell cultures. 


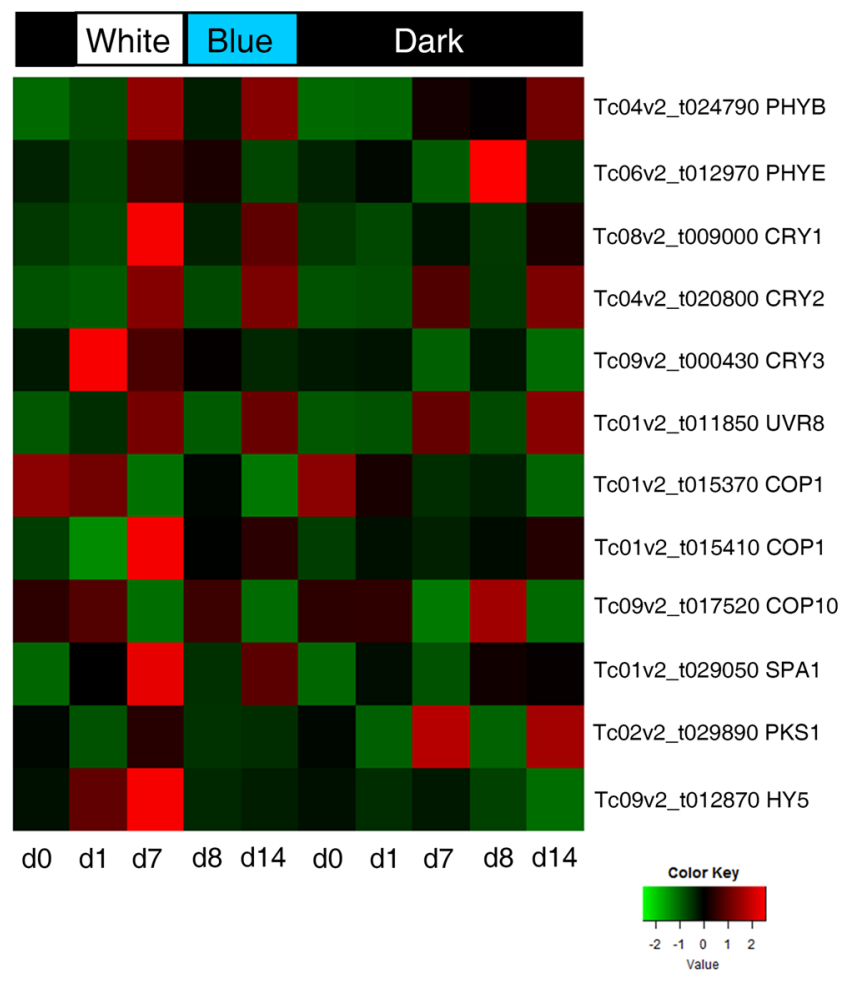

Figure 6. Heat map of selected light signaling genes over time in white-blue light versus dark. Treatments are summarized at the bottom. To the right are the codes assigned for each gene. Abbreviations: day (d).

As expected, major differences were observed between W-B and D regarding expression of photoreceptors. In this first line of genetic regulation immediate responses occur to specific wavelengths corroborating functional data gathered in Arabidopsis ${ }^{58}$. Additionally, our data provides evidence that production of phenolics also occurs in a light independent manner as demonstrated by the results from the cacao cultures incubated in the dark. This would suggest that photoreception is not essential for biosynthesis of phenolics in vitro. It is possible that blue light increases phenolic compounds as a defense mechanism as suggested by the early and strong response under the light change when compared to the dark.

Downstream of the light signaling genes we identified the MYB, bHLH and WD40 (MBW) transcription factors complex involved in the flavonoid pathway which binds to promoters of structural genes, including ANR and $L A R^{59-62}$. The TT2-TT8-TTG1 complex controls the expression of the late biosynthetic genes promoting the accumulation of $\mathrm{PAs}^{16,18}$. In our data, several genes belonging to MYB and bHLH were found and the TTG1 homolog in cacao (Tc03v2_t017390) with a WD40 domain was detected (Fig. 5). Three different expression trends were recorded for MYB genes. Those from the S5 group were expressed in a light independent manner at $\mathrm{d} 0$ and $\mathrm{d} 1$, whereas $M Y B 12$, was the only member of the S7 group expressed at $\mathrm{d} 1$ and $\mathrm{d} 7$ exclusively in the $\mathrm{W}-\mathrm{B}$ treatment. S5 genes like Tc-MYBPA (Tc01v2_t028420) regulate PA synthesis by direct regulation of $L A R$ and $A N R$ both in grape and in cacao ${ }^{26,63}$, explaining polyphenol accumulation during both, $\mathrm{W}-\mathrm{B}$ and $\mathrm{D}$ light regimes. Nevertheless, the difference of MYB12 alone during the time course of the experiment in W-B when compared to $\mathrm{D}$ could result in earlier polyphenol production. Consistent with previously published reports from Arabidopsis, tobacco, and grape, our data suggests that the MYB12 act as flavonol-specific activator induced only by the light treatment ${ }^{29,64,65}$. These results suggest that in in vitro cultures MYB proteins act as activators of the flavonoid synthesis pathway, similarly to their function in planta and that MYB12 could be a candidate gene for manipulation of light induced flavonoid biosynthesis in cell suspension cultures.

The remaining $M Y B$ genes from group S4, well known repressors of the flavonoid pathway, include AtMYB3, $A t M Y B 7, A t M Y B 4$, and AtMYB32 among others ${ }^{66}$. At $\mathrm{d} 7$ and $\mathrm{d} 14$ in both $\mathrm{W}-\mathrm{B}$ and $\mathrm{D}$ treatments most repressors were up-regulated, immediately after the peaks of up-regulation for most of MYBs activators. A similar expression pattern has been recorded for $V v M Y B C 2 L 1$ in grape berry development ${ }^{67}$. Interestingly, three cacao paralogs appear nested in the same subclade with $V v M Y B C 2 L 1$, suggesting cacao specific duplicates with repressive roles. Besides the function of $S 4$ genes in negatively regulating the synthesis of phenolic compounds, they have been shown to fine tune flavonoid levels in grape ${ }^{68}$. Altogether, the fine tuning of $M Y B$ activators and repressors in the time course, in addition to the exclusive upregulation of MYB12 in the light, could explain the catechin profile differences among treatments.

As for the bHLH genes, the expression pattern of Tc-MYC-2 and Tc-bHLH3 was similar to that of S4 MYBs repressors, however a crosstalk between bHLH and MYB repressors has not been reported. The bHLH homologs found here are involved in the positive regulation of flavonoids in other plant species ${ }^{69-71}$. MYC2 positively regulates flavonoid biosynthesis in response to jasmonate (JA) in Arabidopsis ${ }^{72}$. The targeted search for Jasmonic 
acid-amido synthetase in our analyses revealed its upregulation at $\mathrm{d} 8$-VS-d14, which could explain the downstream flavonoid accumulation by TcMYC-2. In addition, MYC2 has been linked to anthocyanin synthesis ${ }^{69}$, but in cacao cell suspensions, Tc-MYC-2 seems to also regulate PA synthesis. The expression of $T c-b H L H 3$, which is turned on at $\mathrm{d} 7 \mathrm{in} \mathrm{W}-\mathrm{B}$ and at $\mathrm{d} 14$ in $\mathrm{D}$, reveals that in cacao cell cultures this gene is active in a light independent manner. The interaction between bHLH3 and MYB12 is known to promote PA synthesis in red-fleshed apple $\mathrm{e}^{73}$, thus, as Tc-bHLH3 and Tc-MYB12 only overlap in W-B at $\mathrm{d} 7$ their interaction could only explain PAs synthesis in the light. However, PAs are also synthesized in D, suggesting that in the dark Tc-bHLH3 has alternative partners. Finally, the cacao homolog in the WD-40 clade, named TTG1 presented a co-regulation with TcMYB330 (a MYB repressor, the ortholog of AtMYB3) with upregulation at d1 for both treatments. No reports are available for interactions between TTG1 and MYB3 homologs, except for the interaction between the MYB homolog repressor of anthocyanins CAPRICE (CPC) and TTG1 in Arabidopsis ${ }^{74,75}$. Based on our co-expression data, we hypothesize that in cacao cell cultures Tc-TTG1 and Tc-MYB330 are likely interacting, but their contribution to flavonoid biosynthesis is still unclear and further functional analysis should be done.

Downstream of the TFs are the structural genes of the flavonoid pathway. Two key structural enzymes unique to PA biosynthesis and which determine the catechin profiles are anthocyanidin reductase (ANR) and leucoanthocyanidin reductase $(L A R)^{76}$. Differences in concentration of $(+)$-catechin between $\mathrm{W}-\mathrm{B}$ and $\mathrm{D}$ could be attributed to differences in expression of $A N R$ or, more likely, $L A R$ (Fig. 3). ANR in tea participates in the production of both epicatechin and catechin using cyanidin as substrate $e^{77}$. Thus, it is possible that the same role is maintained in cacao cell cultures. More interesting is the differential regulation of $L A R$, as this enzyme catalyzes the synthesis of catechin (2,3-trans-flavan-3-ol) from 3,4-cis-leucocyanidin ${ }^{55}$. TcLAR was upregulated three-fold at d7-VS-d8 in W-B and one-fold in D. Overexpression of TcLAR in tobacco produced more epicatechin than catechin ${ }^{25}$, the opposite of what is seen in cacao cultures where more TcLAR results in a 2 -fold increase of catechin in W-B. This suggests differences between the heterologous transformation versus the endogenous activation of TcLAR in cacao cell cultures. Similarly, when TcLAR is overexpressed in ldox (ans) Arabidopsis mutants, which are impaired in anthocyanins and PAs synthesis, there is a significant increase of catechin, but also a slight increase of epicatechin $^{25}$. The same dual functionality of $L A R$ was recently demonstrated in Medicago, where LAR converts $4 \beta$-(S-cysteinyl)- epicatechin back to epicatechin, the starter unit in PAs polymerization ${ }^{78}$. TcLAR has also been evaluated in vitro where it lacks a dual enzymatic activity as shown by the exclusive catechin synthesis ${ }^{25}$. Our data is consistent with the in vitro data, as catechin synthesis preferentially occurred at $\mathrm{d} 7 \mathrm{vs} \mathrm{d} 8$ at WB during TcLAR overexpression. Altogether, the available data points to differential roles of TcLAR in vivo and in vitro, postulating this enzyme as a key target for metabolic engineering able to modify catechin profiles in cell suspensions.

Functional differences of TcLAR in W-B versus D could also be explained by changes in the interacting partners (Fig. 4). Our co-expression analyses revealed that in W-B, TcLAR had a strong interaction with GAT12 (GATA transcription factor 12), also present in the top 30 differentially expressed genes. GATA mediates the crosstalk between brassinosteroids (BR) and light-signaling pathways ${ }^{79}$. Additionally, the relation between the $\mathrm{BR}$ and the flavonoid pathway has been reported ${ }^{80}$. Thus, it is possible that BR modulates catechin production in cacao cell cultures. The metabolism in the $\mathrm{D}$ treatment is far less specialized, as both ANS and LAR interact with CYP76B6 (Putative Geraniol 8-hydroxylase), a cytochrome P450 monooxygenase involved in the biosynthesis of iridoid monoterpenoids ${ }^{81}$ which participate in general signaling of secondary metabolites in cell cultures. The co-expression analysis comparison results in a change from shared partners among ANS, ANR and LAR in the dark to a specialized network for each enzyme in W-B, suggesting different functional capabilities for these enzymes under light in vitro.

The cross-talk between light regulated genes, transcription factors and flavonoids is one of the most promising for increased flavonoid production in crops and likely improved food quality ${ }^{27,50}$. The existence of light regulatory units (LRUs) in the promoter region of structural genes like CHS, $F 3 H$ and $F L S^{28,82}$ suggest their direct regulation by light, however for late genes including $A N S, A N R$ and $L A R$ it remains unknown. Here we show that exposure of cacao cell cultures to different light treatments results in catechin profile changes and provide a platform for dissecting complex genetic networks. Cell cultures allowed the synchronizing of the light signaling responses due to their homogeneity. We determined that light can effectively regulate flavonoid profiles as it changes catechin to epicatechin ratios and we postulated candidate genes (MYB12, HY5, ANR and $L A R$ ) as potential targets of genetic engineering to manipulate the production of cacao polyphenols. Co-expression networks further revealed that light promotes specialization of interacting partners for late biosynthetic genes. Further functional analysis will provide a deeper understanding of the regulatory network of the biosynthesis of catechins. The in vitro cacao cell suspension system and the DEGs identified in this study will enable the development of new biotechnological tools for the generation of value-added plants with optimized flavonoid content.

\section{Materials and Methods}

Plant Material and growth conditions. Mature, eight-month-old cacao pods of the Trinitario ecotype (coded as BIOA) were collected in the commercial crops of Compañía Nacional de Chocolates in the region of San Vicente de Chucurí- Santander, Colombia ( $\left.06^{\circ} 53^{\prime} 00^{\prime \prime} \mathrm{N} ; 73^{\circ} 24^{\prime} 50^{\prime \prime} \mathrm{W}\right)$. Cacao cell suspensions were induced following Gallego et al. ${ }^{83}$. The cultures were maintained at $23 \pm 2{ }^{\circ} \mathrm{C}$ under cool-white fluorescent lamps $\left(12 \mu \mathrm{mol} \mathrm{m}{ }^{-2} . \mathrm{s}^{-1}\right)$ for 16 hours light at $100 \mathrm{rpm}$. After 12 days, cell suspensions were filtered using a $300 \mu \mathrm{m}$ mesh and an inoculum (4g/L dry weight) was used for establishing cultures. These were sub-cultured every 7 days under dark conditions in order to prepare the suspensions for light treatments (see below). Media composition was prepared according to Gallego et al. ${ }^{83}$

Light treatments. Cell suspension cultures were exposed to two light treatments during a time course of 14 days using light-emitting diode (LED) lights. In the first treatment, we evaluated a sequential exposure to white LED followed by exposure to blue LED 7 days each (W-B). In the second treatment, cells were kept in the dark 
for 14 days (D). In both treatments, the day 0 was considered as the reference point for flavonoid production and fresh media was added on day 7 . White and blue LED arrays were designed to give an intensity of $60 \mu \mathrm{mol}$ $\mathrm{m}^{-2} \mathrm{~s}^{-1}$ under a photoperiod of 16 hours light and 8 hours dark. Erlenmeyer flasks of $100 \mathrm{~mL}$ containing $30 \mathrm{~mL}$ of cells were sampled at days $0,1,7,8$ and 14 during the time course. Four replicates were collected for each time point and treatment (W-B and D). Cell suspension samples were preserved in RNA Later ${ }^{\circledR}$ (ratio 1:5) and stored at $-20^{\circ} \mathrm{C}$.

Quantification of total polyphenols, catechins and proanthocyanidins (PAs). Extraction and quantification of total polyphenol content (TPC) were performed following Londoño et al. ${ }^{84}$ on days 0,7 , and 14 during the time course. Dried powdered samples $(50-100 \mathrm{mg})$ were extracted with a mixture of water/isopropyl alcohol mix (40:60) and sonicated for 1 hour with A 96 $=230$ watts (Misonix, S-4000, USA). Samples were centrifuged at $10,000 \mathrm{rpm}$ for 5 minutes at $4{ }^{\circ} \mathrm{C}$. The supernatant was transferred and taken to known volume with distilled water. Folin-Ciocalteau method was used to quantify according to Londoño et al. ${ }^{84}$. Polyphenol extracts were injected in a High-Performance Liquid Chromatographer (HPLC, Agilent Technologies, series 1260), equipped with quaternary pump, automatized injector, fluorescent detector (FLD) and diode-array detector (DAD). A total of $200 \mu \mathrm{l}$ of each extract were diluted to $2 \mathrm{ml}$ using acetic acid solution $0.1 \%$. Chromatographic resolution of analytes in the extracts were made through a Zorbax Eclipse XD-C18 column $(4.6 \times 250 \mathrm{~mm}, 5 \mu \mathrm{m}$ particle size) with constant flow of $1 \mathrm{~m} / \mathrm{min}$. Mobile phases were acetic acid $0.1 \%$ as A solvent and methanol as B solvent, starting in $10 \%$ B for $6 \mathrm{~min}$, after $20 \%$ for $14 \mathrm{~min}$, up again to $22.5 \%$ for $3 \mathrm{~min}$, down $20 \%$ for $8 \mathrm{~min}$ and lastly returned to the initial conditions for $6 \mathrm{~min}$. Total running time was $37 \mathrm{~min}$. Catechins $((+)-$ catechin and (-)- epicatechin)) were measured using HPLC and were monitored in the fluorescent detector at PMT 10 (photomultiplicator) with excitation and emission wavelengths of 280 and $315 \mathrm{~nm}$ respectively. The average values of three independently sampled suspensions were calculated. Extraction and quantification of proanthocyanidins were according Liu et al. ${ }^{25}$. In short, dried $50 \mathrm{mg}$ of suspensions were used to extract consecutively soluble and insoluble PAs with acetone:water:acetic acid (70\%:29.5\%:0.5\%) and buthanol: $\mathrm{HCl}$ (95\%:5\%) respectively. The colorimetric p-dimethylamino-cinnamaldehyde (DMACA) method was used for quantification of soluble PAs. Absorption was measured at $640 \mathrm{~nm}$ and procyanidin B2 was used as standard for quantification. For insoluble PAs, absorbance was measured at $550 \mathrm{~nm}$ and PAs were calculated as cyaniding equivalents using cyanidin 3 glucoside. Soluble and insoluble PAs were added to give the total PAs content.

RNA extraction, library preparation and sequencing. Four replicates were sampled at each time point ( $\mathrm{d} 0, \mathrm{~d} 1, \mathrm{~d} 7, \mathrm{~d} 8$ and $\mathrm{d} 14)$ from the W-B and D treatments for total of 36 samples. Total RNA was extracted from each cell suspension taking $0.1 \mathrm{~mL}$ approximately of pellet volume using combined protocols of PureLink Plant RNA Reagent (Ref: 12322012, Thermo Fisher Scientific) and RNeasy Plus Universal Mini Kit (Cat No. 73404, QIAGEN) following the manufacturer's protocol. RNA concentrations and quality were measured using an Agilent 2100 bioanalyzer and a minimal RIN number of 7 was used for sequencing. The construction of the cDNA libraries and RNAseq were performed by the Genomics Core Facility at Penn State University (University Park, USA). cDNA libraries were prepared with a TruSeq stranded mRNA library prep Kit (cat\# RS-122-2101, Illumina, San Diego, CA, USA). The libraries were sequenced on a HiSeq ${ }^{\mathrm{TM}} 2500$ (Illumina) using single-end runs of $100 \mathrm{nt}$.

Mapping and functional annotation. Quality parameters including GC-content and phred scores were applied to filter the reads. After filtrate low quality raw reads, mapping to the Criollo Cacao Genome V $2^{85}$ was performed by using HISAT $^{86}$. The sequences were annotated using Blast2Go (e-value $<10^{-5}$ ) and the Cacao genome as a reference ${ }^{87}$. The following public protein databases were used for the enrichment analyses: Clusters of Orthologous Groups (COGs) ${ }^{88}$, Kyoto Encyclopedia of Genes and Genomes (KEGG) ${ }^{89}$, and Gene Ontology $(\mathrm{GO})$ protein database $\mathrm{e}^{90}$. Gene expression levels were normalized and differential expression analyses were conducted using Deseq2 $2^{91,92}$. Three pairwise comparisons were performed within each W-B and D condition to identify differentially expressed genes (DEGs) at different time points. Comparisons were made between 0 and 1 day (d0-VS-d1), 7 and 8 days (d7-VS-d8) and 8 and 14 days (d8-VS-d14). DEGs were identified when the False Discovery Rate (FDR) was $\leq 0.05$ and $p$-value was $<0.05$. These putative DEGs were similarly subjected to Gene Ontology (GO) enrichment analysis and KEGG Pathway enrichment analysis to investigate functions and pathways affected over the time course. GO and KEGG enrichment analyses were performed using KOBAS software K3 $^{93}$ to test the statistical enrichment of terms associated with DEGs. Mapman ${ }^{94}$ was used to complement the analysis of pathway regulation from KEGG. A FDR $<0.05$ was used as the threshold to determine significant GO/KEGG enrichment of the gene sets. Additionally, we used the Plant Transcription Factor Database ${ }^{95}$ to annotate DEGs in all the pairwise comparisons with the best transcription factor hits in Arabidopsis thaliana.

Phylogenetic analyses of differentially expressed transcription factors genes. Three different phylogenetic analyses were performed. The first two included differentially expressed transcription factors belonging to the MYB (53) and bHLH (45) gene families with the reported homologs present in the Arabidopsis thaliana genome ${ }^{19,96}$ in order to identify orthologous genes. Full coding sequences from $144 b H L H$ genes and $125 M Y B$ from Arabidopsis were retrieved from Phytozome ${ }^{97}$. A third analysis was done including twelve cacao MYB genes involved in the flavonoid biosynthesis pathway in a larger matrix consisting of $9 M Y B$ genes from Arabidopsis and 5 MYBs from grape (including VvMYBC2-L1 ${ }^{68}, \mathrm{VvMYBPA}^{63}, \mathrm{VvMYBPA}^{98}, \mathrm{VvMYBF} 1^{29}$ and VvMYB5 $^{99}$ ) also retrieved from Phytozome. Full coding sequences of transcription factors (TFs) aligned with the ClustalW algorithm were used to construct the phylogenetic trees using RAxML ${ }^{100}$ in CIPRES Gateway platform $^{101}$. Up to 1000 Bootstrap replicates were run to assess support for the clades found. 
Correlation analysis. A weighted gene co-expression network was constructed using WGCNA R package ${ }^{48}$ with RNA-seq count data. All expressed genes under W-B and D conditions were normalized and genes with low counts (raw counts) lower than 50 were removed. Networks were visualized using Cytoscape V3.5.1 ${ }^{102}$. To simplify the display of the network and to focus on relevant relationships, only edges of the corresponding TOM similarity measure above a threshold of 0.23 are shown. Special attention was given to the top 10 of genes associated with each $A N S, A N R$ and $L A R$, the late structural genes of the flavonoid pathway.

Quantitative PCR. Real-time quantitative reverse transcription-PCR (qRT-PCR) was used to validate gene expression patterns identified by the RNAseq analysis. Aliquots from the RNA used for RNAseq experiments were used as template for cDNA synthesis. RNA was treated with RNase-free DNase (Promega, Cat. M6101) following the manufacturer's protocol. A total of $0.3 \mu \mathrm{g}$ of treated RNA were reverse transcribed by MMuLV Reverse Transcriptase (New England Biolabs, Ipswich, MA, USA) using oligo-(dT)15 primers. Primers were designed for CHS, CHI, DFR, ANS, ANR, LAR, TT2-like and NAC based on the sequences available for the Criollo genome database. ACTIN-7 and UBIQUITIN were selected as endogenous controls. qRT-PCR was performed in a total reaction volume of $10 \mu \mathrm{L}$ containing $4 \mu \mathrm{L}$ of diluted cDNA (1:8), $5 \mu \mathrm{L}$ of SYBR Premix, $0.2 \mu \mathrm{L}$ of Rox (TaKaRa, Mountain View, CA, USA), and $0.4 \mu \mathrm{L}$ of each $5 \mu \mathrm{M}$ primer. Four technical replicates were made for each sample. qRT-PCR was conducted in a real time PCR System (Applied Biosystem Step One Plus, Nutley, NJ, USA).

Statistical analysis. Statistical significance of gene expression between pairwise comparisons was determined analyzing integral readcounts per gene with DESeq2 ${ }^{92}$. ANOVA and TuckeyHSD test were used in the statistical analysis of phenolic quantifications using R software.

\section{Data Availabitlity}

The RNA-Seq data used in this research is available in NCBI with GEO/AdrianaGallego.

\section{References}

1. Lamuela-Raventos, R. M. Review: Health Effects of Cocoa Flavonoids. Food Sci. Technol. Int. 11, 159-176, https://doi. org/10.1177/1082013205054498 (2005).

2. War, A. et al. Mechanisms of Plant Defense against Insect Herbivores. Plant Signal. Behav. 7, 1306-1320, https://doi.org/10.4161/ psb.21663 (2012).

3. Mierziak, J., Kostyn, K. \& Kulma, A. Flavonoids as Important Molecules of Plant Interactions with the Environment. Molecules 16240-16265; https://doi.org/10.3390/molecules191016240 (2014).

4. Chaves, F. C. \& Gianfagna, T. J. Cacao leaf procyanidins increase locally and systemically in response to infection by Moniliophthora perniciosa basidiospores. Physiol. Mol. Plant Pathol. 70, 174-179 (2007).

5. Schulz, E., Tohge, T., Zuther, E., Fernie, A. R. \& Hincha, D. K. Flavonoids are determinants of freezing tolerance and cold acclimation in Arabidopsis thaliana. Sci. Rep. 6, 34027, https://doi.org/10.1038/srep34027 (2016).

6. Nakabayashi, R. et al. Enhancement of oxidative and drought tolerance in Arabidopsis by overaccumulation of antioxidant flavonoids. Plant J. 77, 367-379, https://doi.org/10.1111/tpj.12388 (2014).

7. Ghasemzadeh, A., Jaafar, H. Z. E., Rahmat, A., Edaroyati, P. \& Wahab, M. Effect of Different Light Intensities on Total Phenolics and Flavonoids Synthesis and Anti-oxidant Activities in Young Ginger Varieties (Zingiber officinale Roscoe). Int. J. Mol. Sci. 11, 3885-3897, https://doi.org/10.3390/ijms11103885 (2010).

8. Lois, R. Accumulation of UV-absorbing flavonoids induced by UV-B radiation in Arabidopsis thaliana L. Planta. 194, 498-503 (1994).

9. Falcone Ferreyra, M. L., Rius, S. P. \& Casati, P. Flavonoids: biosynthesis, biological functions, and biotechnological applications. Front. Plant Sci. 3, 1-15, https://doi.org/10.3389/fpls.2012.00222 (2012).

10. Del Valle, J. C., Buide, M. L., Casimiro-Soriguer, I., Whittall, J. B. \& Narbona, E. On flavonoid accumulation in different plant parts: variation patterns among individuals and populations in the shore campion (Silene littorea). Front. Plant Sci. 6, 1-13, https://doi. org/10.3389/fpls.2015.00939 (2015).

11. Wollgast, J. \& Anklam, E. Review on polyphenols in Theobroma cacao: Changes in composition during the manufacture of chocolate and methodology for identification and quantification. Food Res. Int. 33, 423-447, https://doi.org/10.1016/S09639969(00)00068-5 (2000).

12. Shahidi, F. \& Naczk, M. Phenolics in food and nutraceuticals. (ed CRC Press) https://doi.org/10.1016/j.tifs.2004.02.006 (2006).

13. Aprotosoaie, A. C., Luca, S. V. \& Miron, A. Flavor Chemistry of Cocoa and Cocoa Products - An Overview. Compr. Rev. Food Sci. Food Saf. 15, 73-91, https://doi.org/10.1111/1541-4337.12180 (2016).

14. Latif, R. Chocolate/cocoa and human health: a review. Neth. J. Med. 71, 63-8 (2013).

15. Dower, J. I. et al. Effects of the pure flavonoids epicatechin and quercetin on vascular function and cardiometabolic health: A randomized, double-blind, placebo-controlled, crossover trial. Am. J. Clin. Nutr. 101, 914-921, https://doi.org/10.3945/ ajcn.114.098590 (2015).

16. Li, S. Transcriptional control of flavonoid biosynthesis Fine-tuning of the MYB-bHLH-WD40 (MBW) complex. Plant Signal. Behav. 40, 1-7, https://doi.org/10.4161/psb.27522 (2014).

17. Lloyd, A. et al. Advances in the MYB-bHLH-WD Repeat (MBW) Pigment Regulatory Model: Addition of a WRKY Factor and Co-option of an Anthocyanin MYB for Betalain Regulation. Plant Cell Physiol. 0, 1-11, https://doi.org/10.1093/pcp/pcx075 (2017).

18. Xu, W., Dubos, C. \& Lepiniec, L. Transcriptional control of flavonoid biosynthesis by MYB-bHLH-WDR complexes. Trends Plant Sci. 20, 176-185, https://doi.org/10.1016/j.tplants.2014.12.001 (2015).

19. Dubos, C., Stracke, R., Grotewold, E., Weisshaar, B. \& Martin, C. MYB transcription factors in Arabidopsis. Cell 15, 573-581, https://doi.org/10.1016/j.tplants.2010.06.005 (2010).

20. Paz-Ares, J., Wienand, U., Peterson, P. A. \& Saedler, H. Molecular cloning of the c locus of Zea mays: a locus regulating the anthocyanin pathway. EMBO J. 5, 829-33 (1986).

21. De Vetten, N., Quattrocchio, F., Mol, J. \& Koes, R. The an 11 locus controlling flower pigmentation in petunia encodes a novel WDrepeat protein conserved in yeast, plants, and animals. Genes Dev. 11, 1422-1434 (1997).

22. Walker, A. R. et al. The TRANSPARENT TESTA GLABRA1 locus, which regulates trichome differentiation and anthocyanin biosynthesis in Arabidopsis, encodes a WD40 repeat protein. Plant Cell 11, 1337-1349 (1999).

23. Schwinn, K. A Small Family of MYB-Regulatory Genes Controls Floral Pigmentation Intensity and Patterning in the Genus Antirrhinum. Plant Cell Online 18, 831-85, https://doi.org/10.1105/tpc.105.039255 (2006).

24. Albert, N. W. et al. A Conserved Network of Transcriptional Activators and Repressors Regulates Anthocyanin Pigmentation in Eudicots. Plant Cell 26, 962-980, https://doi.org/10.1105/tpc.113.122069 (2014). 
25. Liu, Y., Shi, Z., Maximova, S., Payne, M. J. \& Guiltinan, M. J. Proanthocyanidin synthesis in Theobroma cacao: genes encoding anthocyanidin synthase, anthocyanidin reductase, and leucoanthocyanidin reductase. BMC Plant Biol. 13, 1-19, https://doi. org/10.1186/1471-2229-13-202 (2013).

26. Liu, Y., Shi, Z., Maximova, S. N., Payne, M. J. \& Guiltinan, M. J. Tc-MYBPA is an Arabidopsis TT2-like transcription factor and functions in the regulation of proanthocyanidin synthesis in Theobroma cacao. BMC Plant Biol. 15, 1-16, https://doi.org/10.1186/ s12870-015-0529-y (2015).

27. Bai, S. et al. Transcriptome analysis of bagging-treated red Chinese sand pear peels reveals light-responsive pathway functions in anthocyanin accumulation. Sci. Rep. 7, 63, https://doi.org/10.1038/s41598-017-00069-z (2017).

28. Hartmann, U., Sagasser, M., Mehrtens, F., Stracke, R. \& Weisshaar, B. Differential combinatorial interactions of cis-acting elements recognized by R2R3-MYB, BZIP, and BHLH factors control light-responsive and tissue-specific activation of phenylpropanoid biosynthesis genes. Plant Mol. Biol. 57, 155-171, https://doi.org/10.1007/s11103-004-6910-0 (2005).

29. Czemmel, S. et al. The Grapevine R2R3-MYB Transcription Factor VvMYBF1 Regulates Flavonol Synthesis in Developing Grape Berries. Plant Physiol. 151, 1513-1530, https://doi.org/10.1104/pp.109.142059 (2009).

30. Saito, K. et al. The flavonoid biosynthetic pathway in Arabidopsis: Structural and genetic diversity. Plant Physiol. Biochem. 72, 21-34, https://doi.org/10.1016/j.plaphy.2013.02.001 (2013).

31. Petrussa, E. et al. Plant flavonoids-biosynthesis, transport and involvement in stress responses. Int. J. Mol. Sci. 14, 14950-14973, https://doi.org/10.3390/ijms140714950 (2013).

32. Albert, N. W. et al. Members of an R2R3-MYB transcription factor family in Petunia are developmentally and environmentally regulated to control complex floral and vegetative pigmentation patterning. Plant J. 65, 771-784, https://doi. org/10.1111/j.1365-313X.2010.04465.x. (2011).

33. Zoratti, L., Karppinen, K., Luengo Escobar, A., Häggman, H. \& Jaakola, L. Light-controlled flavonoid biosynthesis in fruits. Front. Plant Sci. 5, 534 10.3389/fpls.2014.00534 (2014).

34. Maier, A. et al. Light and the E3 ubiquitin ligase COP1/SPA control the protein stability of the MYB transcription factors PAP1 and PAP2 involved in anthocyanin accumulation in Arabidopsis. Plant J. 74, 638-651, https://doi.org/10.1111/tpj.12153 (2013).

35. Chen, M., Chory, J. \& Fankhauser, C. Light Signal Transduction in Higher Plants. Annu. Rev. Genet. 38, 87-117, https://doi. org/10.1146/annurev.genet.38.072902.092259 (2004).

36. Agati, G. \& Tattini, M. Multiple functional roles of flavonoids in photoprotection. New Phytol. 186, 786-793, https://doi. org/10.1111/j.1469-8137.2010.03269.x (2010).

37. Palapol, Y., Ketsa, S., Ferguson, I. B. \& Allan, A. C. A. MYB transcription factor regulates anthocyanin biosynthesis in mangosteen (Garcinia mangostana L.) fruit during ripening. Planta. 8, 1323-1334, https://doi.org/10.1007/s00425-009-0917-3 (2009).

38. Lei, H. A. N. et al. Effect of Light on Flavonoids Biosynthesis in Red Rice Rdh. Agric. Sci. China 8, 746-752, https://doi.org/10.1016/ S1671-2927(08)60274-6 (2009).

39. Zheng, Y. et al. Anthocyanin profile and gene expression in berry skin of two red Vitis vinifera grape cultivars that are sunlight dependent. Aust. J. Grape Wine Res. 19, 238-248, https://doi.org/10.1111/ajgw.12023 (2013).

40. Jiao, Y., Lau, O. S. \& Deng, X. W. Light-regulated transcriptional networks in higher plants. Nat. Rev. Genet. 8, 217-230, https://doi. org/10.1038/nrg2049 (2007).

41. Carbone, F. et al. Developmental, genetic and environmental factors affect the expression of flavonoid genes, enzymes and metabolites in strawberry fruits. Plant, Cell Environ. 32, 1117-1131, https://doi.org/10.1111/j.1365-3040.2009.01994.x (2009).

42. Menges, M., Hennig, L., Gruissem, W. \& Murray, J. A. H. Genome-wide gene expression in an Arabidopsis cell suspension. Plant Mol. Biol. 53, 423-442, https://doi.org/10.1023/B:PLAN.0000019059.56489.ca (2003).

43. Seo, J. M., Arasu, M. V., Kim, Y. B., Park, S. U. \& Kim, S. J. Phenylalanine and LED lights enhance phenolic compound production in Tartary buckwheat sprouts. Food Chem. 177, 204-213, https://doi.org/10.1016/j.foodchem.2014.12.094 (2015).

44. Manivannan, A., Soundararajan, P., Halimah, N., Ko, C. H. \& Jeong, B. R. Blue LED light enhances growth, phytochemical contents, and antioxidant enzyme activities of Rehmannia glutinosa cultured in vitro. Hortic. Environ. Biotechnol. 56, 105-113 (2015).

45. Ballester, A. R. \& Lafuente, M. T. LED Blue Light-induced changes in phenolics and ethylene in citrus fruit: Implication in elicited resistance against Penicillium digitatum infection. Food Chem. 218, 575-583, https://doi.org/10.1016/j.foodchem.2016.09.089 (2017).

46. Arias, J. P., Zapata, K., Rojano, B. \& Arias, M. Effect of light wavelength on cell growth, content of phenolic compounds and antioxidant activity in cell suspension cultures of Thevetia peruviana. J. Photochem. Photobiol. B Biol. 163, 87-91, https://doi. org/10.1016/j.jphotobiol.2016.08.014 (2016).

47. Rojas, L. F., Gallego, A., Gil, A., Londono, J. \& Atehortua, L. Monitoring accumulation of bioactive compounds in seeds and cell culture of Theobroma cacao at different stages of development. Vitr. Cell. Dev. Biol. 51, 174-184; 174-184; https://doi.org/10.1007/ s11627-015-9684-y (2015).

48. Langfelder, P. \& Horvath, S. WGCNA: an R package for weighted correlation network analysis. BMC Bioinformatics 9 , 559, https:// doi.org/10.1186/1471-2105-9-559 (2008)

49. Du, H., Feng, B., Yang, S., Huang, Y. \& Tang, Y. The R2R3-MYB transcription factor gene family in maize. PLoS One 7, 1-12, https://doi.org/10.1371/journal.pone.0037463 (2012).

50. Zhang, H. N. et al. Transcriptome profiling of light-regulated anthocyanin biosynthesis in the pericarp of Litchi. Front. Plant Sci. 7(963), 1-15, https://doi.org/10.3389/fpls.2016.00963 (2016).

51. Papers, J. B. C. et al. Light-dependent, dark-promoted interaction between arabidopsis cryptochrome 1 and phytochrome B proteins. J. Biol. Chem. 287, 22165-22172, https://doi.org/10.1074/jbc.M112.360545 (2012).

52. Facella, P. et al. CRY-DASH gene expression is under the control of the circadian clock machinery in tomato. FEBS Lett. 580, 4618-4624, https://doi.org/10.1016/j.febslet.2006.07.044 (2006).

53. Vandenbussch, F. et al. HY5 is a point of convergence between cryptochrome and cytokinin signalling pathways in Arabidopsis thaliana. Plant J. 49, 428-441, https://doi.org/10.1111/j.1365-313X.2006.02973.x (2007).

54. Nawkar, G. M., Ho, C., Maibam, P., Hun, J. \& Jun, Y. HY5, a positive regulator of light signaling, negatively controls the unfolded protein response in Arabidopsis. PNAS 114, 1-6, https://doi.org/10.1073/pnas.1609844114 (2017).

55. Tanner, G. J. et al. Proanthocyanidin biosynthesis in plants. J. Biol. Chem. 278, 31647-31656, https://doi.org/10.1074/jbc. M302783200 (2003).

56. Hennig, L., Stoddart, W. M., Dieterle, M., Whitelam, G. C. \& Scha, E. Phytochrome E Controls light-induced germination of Arabidopsis. Plant Physiol. 128, 194-200, https://doi.org/10.1104/pp.010559 (2002).

57. Fankhauser, C. et al. PKS1, a Substrate Phosphorylated by Phytochrome That Modulates Light Signaling in Arabidopsis. Science. 284, 1539-1541 (1999).

58. Kong, S. G. \& Okajima, K. Diverse photoreceptors and light responses in plants. J. Plant Res. 129, 111-114, https://doi.org/10.1007/ s10265-016-0792-5 (2016)

59. Romanowski, A. \& Yanovsky, M. J. Circadian rhythms and post-transcriptional regulation in higher plants. Front. Plant Sci. 6, 1-11, https://doi.org/10.3389/fpls.2015.00437 (2015).

60. Lee, J. et al. Analysis of transcription factor HY5 genomic binding sites revealed its hierarchical role in light regulation of development. Plant Cell Online 19, 731-749, https://doi.org/10.1105/tpc.106.047688 (2007). 
61. Mohanty, B. et al. Light-specific transcriptional regulation of the accumulation of carotenoids and phenolic compounds in rice leaves. Plant Signal. Behav. 11, e1184808, https://doi.org/10.1080/15592324.2016.1184808 (2016).

62. Xu, W. et al. Complexity and robustness of the flavonoid transcriptional regulatory network revealed by comprehensive analyses of MYB-bHLH-WDR complexes and their targets in Arabidopsis seed. New Phytol. 202, 132-144, https://doi.org/10.1111/nph.12620 (2014).

63. Bogs, J., Jaffe, F. W., Takos, A. M., Walker, A. R. \& Robinson, S. P. The grapevine transcription factor vvmybpal regulates proanthocyanidin synthesis during fruit development. Plant Physiol. 143, 1347-1361, https://doi.org/10.1104/pp.106.093203 (2007).

64. Mehrtens, F., Kranz, H., Bednarek, P. \& Weisshaar, B. The Arabidopsis transcription factor myb12 is a flavonol-specific regulator of pheylpropanoid biosynthesis. Plant Physiol. 138, 1083-1096, https://doi.org/10.1104/pp.104.058032 (2005).

65. Pandey, A., Misra, P., Bhambhani, S., Bhatia, C. \& Trivedi, P. K. Expression of Arabidopsis MYB transcription factor, AtMYB111,in tobacco requires light to modulate flavonol content. Sci. Rep. 4, 5018, https://doi.org/10.1038/srep05018 (2014).

66. Zhou, M. et al. Changing a conserved amino acid in R2R3-MYB transcription repressors results in cytoplasmic accumulation and abolishes their repressive activity in Arabidopsis. plant J. 84, 395-403, https://doi.org/10.1111/tpj.13008 (2015).

67. Huang, Y. et al. VvMYBrep, a negative regulator of proanthocyanidin accumulation in grape berry, identified through expression quantitative locus mapping. New Phytol. 201, 795-809, https://doi.org/10.1111/nph.12557 (2014).

68. Cavallini, E. et al. The phenylpropanoid pathway is controlled at different branches by a set of R2R3-MYB C2 repressors in grapevine. Plant Physiol. 167, 1448-1470, https://doi.org/10.1104/pp.114.256172 (2015).

69. Kazan, K. \& Manners, J. M. MYC2: The master in action. Mol. Plant 6, 686-703, https://doi.org/10.1093/mp/sss128 (2013).

70. Ravaglia, D. et al. Transcriptional regulation of flavonoid biosynthesis in nectarine (Prunus persica) by a set of R2R3 MYB transcription factors. BMC Plant Biol. 13, 1-14, https://doi.org/10.1186/1471-2229-13-68 (2013).

71. Espley, R. V. et al. Red colouration in apple fruit is due to the activity of the MYB transcription factor, MdMYB10. Plant J. 49, 414-427, https://doi.org/10.1111/j.1365-313X.2006.02964.x (2007).

72. Dombrecht, B. et al. MYC2 Differentially Modulates Diverse Jasmonate-Dependent Functions in Arabidopsis. Plant Cell Online 19, 2225-2245, https://doi.org/10.1105/tpc.106.048017 (2007).

73. Wang, N. et al. MYB12 and MYB22 play essential roles in proanthocyanidin and flavonol synthesis in red-fleshed apple (Malus sieversii f. niedzwetzkyana). Plant J. 90, 276-292, https://doi.org/10.1111/tpj.13487 (2017).

74. Zhu, H., Fitzsimmons, K., Khandelwal, A. \& Kranz, R. G. CPC, a single-repeat R3 MYB, is a negative regulator of anthocyanin biosynthesis in Arabidopsis. Mol. Plant 2, 790-802, https://doi.org/10.1093/mp/ssp030 (2009).

75. Pesch, M. et al. TRANSPARENT TESTA GLABRA1 and GLABRA1 compete for binding to GLABRA3 in Arabidopsis. Plant Physiol. 168, 584-597, https://doi.org/10.1104/pp.15.00328 (2015).

76. Lu, N., Roldan, M. \& Dixon, R. A. Characterization of two TT2-type MYB transcription factors regulating proanthocyanidin biosynthesis in tetraploid cotton, Gossypium hirsutum. Planta 246, 323-335, https://doi.org/10.1007/s00425-017-2682-z (2017).

77. Zhang, L. Q., Wei, K., Cheng, H., Wang, L. Y. \& Zhang, C. C. Accumulation of catechins and expression of catechin synthetic genes in Camellia sinensis at different developmental stages. Bot. Stud. 57, 3-8, https://doi.org/10.1186/s40529-016-0143-9 (2016).

78. Liu, C., Wang, X., Shulaev, V. \& Dixon, R. A. A role for leucoanthocyanidin reductase in the extension of proanthocyanidins. Nat. Plants 2, 16182, https://doi.org/10.1038/nplants.2016.182 (2016).

79. Luo, X. et al. Integration of light and brassinosteroid signaling pathways by a GATA transcription factor in Arabidopsis. Dev Cell 23, 1-7, https://doi.org/10.1016/j.devcel.2010.10.023 (2010).

80. Petridis, A., Doll, S., Nichelmann, L., Bilger, W. \& Mock, H. P. Arabidopsis thaliana G2-like flavonoid regulator and brassinosteroid enhanced expression are low-temperature regulators of flavonoid accumulation. New Phytol. 211, 912-925, https://doi. org/10.1111/nph.13986 (2016).

81. Collu, G. et al. Geraniol 10-hydroxylase 1, a cytochrome P450 enzyme involved in terpenoid indole alkaloid biosynthesis. FEBS Lett. 508, 215-220 (2001).

82. Weibhaar, B., Feldbrugge, M., Armstrong, G. A. \& Yazaki, K. Elements involved in light regulation of the parsley chs promoter: cis- acting nucleotide sequences and transacting factors. Compte-Rendu Proc (1992).

83. Gallego, A. M. et al. A rational approach for the improvement of biomass production and lipid profile in cacao cell suspensions. Bioprocess Biosyst. Eng. 40, 1479-1492, https://doi.org/10.1007/s00449-017-1805-z (2017).

84. Londoño, J., Montoya, G., Guerrero, K., Aristizabal, L. \& Arango, G. J. Los jugos cítricos inhiben la oxidación de lipoproteínas de baja densidad: Relación entre actividad captadora de radicales libres y modalidad electroforética. Rev Chil Nutr 33, https://doi. org/10.4067/S0717-75182006000500011 (2006).

85. CIRAD. Cocoa Genome Hub. http://cocoa-genome-hub.southgreen.fr/node/4 (2017).

86. Kim, D., Langmead, B. \& Salzberg, S. L. HISAT: a fast spliced aligner with low memory requirements. Nat. Methods 12, 357-60, https://doi.org/10.1038/nmeth.3317 (2015).

87. Argout, X. et al. The genome of Theobroma cacao. Nat. Genet. 43, 101-8, https://doi.org/10.1038/ng.736 (2011).

88. Tatusov, R. L., Galperin, M. Y., Natale, D. A. \& Koonin, E. V. The COG database: a tool for genome-scale analysis of protein functions and evolution. Nucleic Acids Res. 28, 33-36 (2000).

89. Kanehisa, M. \& Goto, S. KEGG: Kyoto encyclopedia of genes and genomes. Nucleic Acids Res. 28, 27-30 (2000).

90. Consortium, T. G. O. Gene ontologie: Tool for the unification of biology. Nat. Genet. 25, 25-29 (2000).

91. Anders, S. \& Huber, W. Differential expression analysis for sequence count data. Genome Biol. 11, R106, https://doi.org/10.1186/ gb-2010-11-10-r106 (2010).

92. Love, M. I., Huber, W. \& Anders, S. Moderated estimation of fold change and dispersion for RNA-seq data with DESeq2. Genome Biol. 15, 550, https://doi.org/10.1186/s13059-014-0550-8 (2014).

93. Xie, C. et al. KOBAS 2.0: A web server for annotation and identification of enriched pathways and diseases. Nucleic Acids Res. 39, 316-322, https://doi.org/10.1093/nar/gkr483 (2011).

94. Usadel, B. et al. A guide to using MapMan to visualize and compare Omics data in plants: A case study in the crop species, Maize. Plant, Cell Environ. 32, 1211-1229, https://doi.org/10.1111/j.1365-3040.2009.01978.x (2009).

95. Jin, J. et al. PlantTFDB 4.0: toward a central hub for transcription factors and regulatory interactions in plants. Nucleic Acids Res. 45, 1040-1045; https://doi.org/10.1093/nar/gkw982 (2017).

96. Toledo-ortiz, G., Huq, E. \& Quail, P. H. The Arabidopsis basic/helix-loop-helix transcription factor family. Plant Cell 15, 1749-1770, https://doi.org/10.1105/tpc.013839 (2003).

97. Goodstein, D. M. et al. Phytozome: a comparative platform for green plant genomics. Nucleic Acids Res. 40, 1178-1186, https://doi. org/10.1093/nar/gkr944 (2012).

98. Vialet, S., Verrie, C., Terrier, N., Torregrosa, L. \& Romieu, C. Ectopic expression of vvmybpa2 promotes proanthocyanidin biosynthesis in grapevine and suggests additional targets in the pathway. Plant Physiol. 149, 1028-1041; https://doi.org/10.1104/ pp.108.131862 (2009)

99. Deluc, L. et al. The transcription factor VvMYB5b contributes to the regulation of anthocyanin and proanthocyanidin biosynthesis in developing grape berries. Plant Physiol. 147, 2041-2053, https://doi.org/10.1104/pp.108.118919 (2008).

100. Stamatakis, A. RAxML version 8: A tool for phylogenetic analysis and post-analysis of large phylogenies. Bioinformatics 30, 1312-1313, https://doi.org/10.1093/bioinformatics/btu033 (2014). 
101. Miller, M. A., Pfeiffer, W. \& Schwartz, T. Creating the CIPRES science gateway for inference of large phylogenetic trees. In Conference'10, Month 1-2, 2010, City, State, Country, https://doi.org/10.1109/GCE.2010.5676129 (2010).

102. Shannon, P. et al. Cytoscape: a software environment for integrated models of biomolecular interaction networks. Genome Res. 13, 12-16, https://doi.org/10.1101/gr.1239303 (2003).

\section{Acknowledgements}

We thank Ruta N (Project number C007), Compañía Nacional de Chocolates and Universidad de Antioquia, Convocatorias de Sostenibilidad 2017-2018 to the Biotecnologia and the Evo Devo en Plantas groups for funding. We also thank the Huck Institutes of the Life Sciences, Genomics and Bioinformatics Core Facilities at Penn State University (PSU), especially to Istvan Albert and Aswathy Sebastian for the support provided with the bioinformatic analyses. We thank the members of the Guiltinan-Maximova lab at PSU, for providing laboratory and office space for the research. Finally, we thank members of the dePamphilis Lab at PSU and particularly Eric Wafula for his contribution with some bioinformatics scripts.

\section{Author Contributions}

A.M.G. conceived the project, did the RNA extractions, qPCR experiments and analyzed the data. L.F.R. conceived the project and assisted with chemical analysis. O.P. and J.C.M.R. performed chemical quantifications. H.A.R. contributed with qPCR validation and the transcriptomic data analysis. A.I.U. assisted in the cell culture establishment, experimental standardization and writing. L.A. established LEDs platforms for in vitro cultures and revised the manuscript. A.S.F. contributed with bioinformatic pipeline and qPCR validation. A.M.G., A.S.F., M.J.G., S.N.M. and N.P.M. designed the experiments, assisted in the data analysis and wrote and revised the manuscript; N.P.M. supervised the research, wrote and discussed with A.M.G. the results.

\section{Additional Information}

Supplementary information accompanies this paper at https://doi.org/10.1038/s41598-018-31965-7.

Competing Interests: The authors declare no competing interests.

Publisher's note: Springer Nature remains neutral with regard to jurisdictional claims in published maps and institutional affiliations.

(c) (i) Open Access This article is licensed under a Creative Commons Attribution 4.0 International License, which permits use, sharing, adaptation, distribution and reproduction in any medium or format, as long as you give appropriate credit to the original author(s) and the source, provide a link to the Creative Commons license, and indicate if changes were made. The images or other third party material in this article are included in the article's Creative Commons license, unless indicated otherwise in a credit line to the material. If material is not included in the article's Creative Commons license and your intended use is not permitted by statutory regulation or exceeds the permitted use, you will need to obtain permission directly from the copyright holder. To view a copy of this license, visit http://creativecommons.org/licenses/by/4.0/.

(C) The Author(s) 2018 